\title{
Evidence-based analysis of odontoid fracture management
}

\author{
Terrence D. Julien, M.D., Bruce Frankel, M.D., Vincent C. Traynelis, M.D., \\ AND Timothy C. RYKen, M.D.
}

Department of Neurosurgery, SUNY Health Science Center at Syracuse, Syracuse, New York; and Division of Neurosurgery, University of Iowa Hospitals and Clinics, Iowa City, Iowa

\begin{abstract}
Object. The management of odontoid fractures remains controversial. Evidence-based methodology was used to review the published data on odontoid fracture management to determine the state of the current practices reported in the literature.

Methods. The Medline literature (1966-1999) was searched using the keywords "odontoid," "odontoid fracture," and "cervical fracture" and graded using a four-tiered system. Those articles meeting selection criteria were divided in an attempt to formulate practice guidelines and standards or options for each fracture type. Evidentiary tables were constructed by treatment type.

Ninety-five articles were reviewed. Five articles for Type I, 16 for Type II, and 14 for Type III odontoid fractures met selection criteria. All studies reviewed contained Class III data (American Medical Association data classification).

Conclusions. There is insufficient evidence to establish a standard or guideline for odontoid fracture management. Given the extent of Class III evidence and outcomes reported on Type I and Type III fractures, a well-designed casecontrolled study would appear to provide sufficient evidence to establish a practice guideline, suggesting that cervical immobilization for 6 to 8 weeks is appropriate management. In cases of Type II fracture, analysis of the Class III evidence suggests that both operative and nonoperative management remain treatment options. A randomized trial or serial case-controlled studies will be required to establish either a guideline or treatment standard for this fracture type.
\end{abstract}

KEY WORDS • odontoid • odontoid fracture • cervical spine

The incidence of traumatic spinal cord injury in the United States is greater than 11,000 cases annually. ${ }^{7,21}$ More than $60 \%$ of spinal injuries affect the cervical spine, and approximately one out of five cases of all cervical spine injuries involve the axis. ${ }^{16,20}$ The most common axis injury is odontoid fracture, of which the majority are Type II or dens fractures. ${ }^{3,5,19}$ They occur at the junction between the odontoid process and the body of C-2, resulting in potentially disastrous instability. The biomechanical design of the C1-2 complex allows for more motion than any other single level in the cervical spine. ${ }^{4}$ This motion is primarily rotational, accounting for half of the axial rotation of the neck. ${ }^{29}$ Translational motion is restricted by the strong transverse ligament containing the odontoid process in the anterior portion of the ring of C-1. All other supporting ligaments are substantially weaker than those in the subaxial spine, facilitating the motion that occurs at this joint. ${ }^{29}$

When the odontoid is fractured, there is no longer significant restriction of translational movements. Anterolisthesis or posterolisthesis, of the C-1 odontoid complex may occur relative to the body of $\mathrm{C}-2$. If a significant degree of movement occurs, the function and integrity of the spinal cord may be jeopardized, possibly resulting in significant neurological deficit. As such, this is one of the most common sites of disruption in fatal cervical spine injuries. ${ }^{1,12}$

The nonoperative treatment modalities for cases in which this type of fracture occurs are either no treatment or immobilization with a cervical fixation device, which includes a cervical collar or halo vest or Minerva jacket immobilization. Patients may also undergo a posterior fusion or anterior fixation procedure in which screws are placed.

A number of practice guidelines have been developed, using a scientific model, that have resulted in not only improved patient care but also a reduction in medical cost and time. ${ }^{30}$ The American Medical Association has suggested that a number of attributes are required for the development of scientifically sound, clinically relevant guidelines. ${ }^{2}$ The most important of these attributes focuses on the methods by which the literature is reviewed and the evidence graded. Data may be classified into four categories: 1) Class I evidence includes data collected in prospective trials, and these trials may or may not be randomized. 2) Class II evidence consists of data that are collected prospectively or retrospectively by using reliable data; Class II studies include cohort studies, preva- 
lence studies, and case-controlled studies. 3) Class III evidence is based on retrospectively collected data; articles that fall into this category would include clinical series, database reviews, and case reviews. 4) Class IV evidence consists of case reports, anecdotal reports, testimony, theory, and common sense. ${ }^{2}$

Treatment recommendations for any given disease entity may be weighted according to the available evidence. ${ }^{26}$ Treatment recommendations are generally divided into three groups. Standards reflect a high degree of clinical certainty, and these are based on Class I data or very strong Class II data. Guidelines reflect a moderate degree of clinical certainty in terms of therapeutic efficacy, and they are usually based on Class II evidence or a preponderance of Class III evidence. Treatment options reflect mild or unclear clinical certainty, and these are usually based on Class III data.

Outcome measures used to determine the success of treatment of odontoid fractures include bone fusion, morbidity, mortality, length and degree of disability cost, and length of hospitalization. For the purpose of this review bone fusion was the only criterion chosen. As such, it is widely recognized that radiographic determination of fusion is difficult to determine and may not coincide with other long-term outcomes such as pain, disability, neurological deficit, and function.

\section{CINICAL MATERIAL AND METHODS}

A Medline search of the English-language literature published from 1966 to 1999 was performed using three key words: odontoid, odontoid fracture, and cervical fracture. Ninety-five articles were identified and reviewed using the following selection criteria: human cases, a minimum follow-up period of 18 months, and the inclusion of 10 or more patients. Of the articles meeting selection criteria, five provided data on Type I, 16 on Type II, and 14 on Type III odontoid fractures.

For the purpose of this review, successful bone fusion was chosen as the only outcome criterion. Other criteria, such as complication rates, patient satisfaction, incidence of long-term disability, as well as numerous others, were less consistently documented. Although inclusion of these data would be of significant interest, for the purposes of this study we elected to use radiologically documented fusion as the sole outcome criterion because this information was more consistently available in the papers reviewed. It is generally known that radiological determination of fusion may be difficult and often imprecise. However, because medical and/or surgical management of odontoid fractures is undertaken to achieve spinal stability and thus radiologically proven fusion, this is an adequate outcome measure to examine. Radiological evidence of bone fusion such as the trabecula crossing the fracture site, as well as absence of motion on flexion-extension x-ray films, is believed to represent a successful fusion. The literature was reviewed with attention to the aforementioned criteria used to determine fusion. In using these constraints, no Class I or Class II data were identified. All Class IV data were eliminated, and therefore all of the available articles used for analysis contained Class III data. The data we obtained were used to construct evidentiary Tables 1 to 4 .

\section{RESULTS}

In a single article the authors studied the course of 18 patients with Type II odontoid fractures and three patients with Type III odontoid fractures who received no treatment (data not shown). ${ }^{10}$ This multicenter review was compiled by the Cervical Spine Research Society. In none of the patients with Type II or III odontoid fractures was fusion demonstrated; therefore, denial of treatment should not be considered as a treatment option.

In nine articles (total 269 patients) the authors treated odontoid fractures with halo/Minerva fixation for 8 to 12 weeks postinjury (Table 1). ${ }^{8-10,14,15,17,22,25,27}$ In three of three patients with Type I fractures successful fusions were demonstrated posttreatment. ${ }^{9,17,27}$ In 110 (65\%) of 168 patients with Type II odontoid fractures treated with halo fixation fusion was demonstrated, whereas in $50(30 \%)$ of 168 patients fusion failed to occur; the remaining cases were described as having evidence of malunion only. In $67(84 \%)$ of 80 patients with Type III odontoid fractures fusion was eventually shown, whereas in six $(8 \%)$ of 80 patients fusion did not occur and there were seven cases of malunions. Age was not clearly a predictor of successful fusion; however, halo immobilization, implicated in the negative outcome in elderly patients, often resulted in increased pulmonary infections and death. The degree of fracture displacement had a negative correlation in four studies. ${ }^{10,14,15,22}$ In three of these the amount of displacement was specified as greater than $2 \mathrm{~mm}, 4 \mathrm{~mm}$, and 6 $\mathrm{mm}$, respectively. ${ }^{10,14,15}$ Immobilization can be considered a treatment option in cases of Types I, II, and III odontoid fractures. Immobilization appears to be most successful in patients with nondisplaced odontoid fractures but should be considered with caution in the elderly patient.

In seven articles containing Class III data the authors treated patients with odontoid fractures by placing them in traction (Table 2). ${ }^{3,9,10,17,18,24,25}$ Radiological evidence of fusion was demonstrated in three of three patients with Type I odontoid fractures. Fusion was found to have occurred in 55 (57\%) of 97 patients with Type II odontoid fractures, whereas it did not occur in $42(43 \%)$ of 97 patients. In 57 (88\%) of 65 patients with Type III odontoid fractures fusion was demonstrated, whereas it failed to occur in only four $(6 \%)$ of 63 patients. Thus, traction followed by cervical collar immobilization can be considered a treatment option especially in patients with Type I and Type III fractures. This modality of treatment is especially useful in cases in which the patient has sustained multiple traumatic injuries and will have an extensive stay in the intensive care unit. However, in cases of Type II odontoid fractures, it must be kept in mind that successful fusion may not occur in almost half of the patients when this treatment modality is applied.

In eight articles containing Class III data the investigators treated odontoid fractures with posterior cervical fixation (Table 3) ${ }^{9-11,14,17,23,25,28}$ In one of one case with Type I odontoid fracture postoperative fusion was eventually demonstrated. In patients with Type II odontoid fractures, radiological fusion was revealed in $109(74 \%)$ of 147 patients. In patients with Type III odontoid fracture, fusion was documented in 28 (97\%) of 29 patients. The rate of surgery-related mortality was between $2 \%$ and $4 \%$, with a major morbidity rate of approximately $2 \%$. Complications 


\section{Management of odontoid fractures}

TABLE 1

Treatment and outcome of odontoid fractures by nonoperative means in cases reported in the literature*

\begin{tabular}{|c|c|c|c|c|}
\hline Authors \& Year & Therapy & Description of Study & $\begin{array}{c}\text { Class of } \\
\text { Data }\end{array}$ & Outcome \\
\hline
\end{tabular}

$\begin{array}{cl}\text { Anderson \& } & \text { traction/ } \\ \text { D'Alzono, } 1974 & \text { collar }\end{array}$

Marar \& Tay, 1976 traction

Ekong, et al., 1981 halo

$\begin{array}{cl}\begin{array}{c}\text { Ryan \& Taylor, } \\ 1982\end{array} & \begin{array}{l}\text { halo/ } \\ \text { Minerva/ } \\ \text { SOMI }\end{array} \\ \begin{array}{c}\text { Clark \& White, } \\ 1985\end{array} & \text { halo }\end{array}$

Pepin, et al., 1985 halo/ traction

Dunn \& Seljeskog, halo 1986

Fuji, et al., $1987 \quad$ halo/

traction

Lind, et al., 1987 halo Govender \&
$\begin{aligned} & \text { Grootboom, } \\ & 1988\end{aligned}$
collar

Bucholz \& Chung, halo 1989

Chiba, et al., 1996 traction/ collar
37 pts: 2 Type I, 22 Type II, 13 Type III (kept in traction for $6 \mathrm{wks}$ and then in cervical brace; radiographic criteria for fusion not provided)

26 pts: 0 Type I, 24 Type II, 2 Type III (radiographic criteria for fusion: fibrous union at fx site)

22 pts w/ C-2 fx involving OP: 0 Type I, 16 Type II, 6 Type III, immobilized for 3 mos in the halo; FU was 6 mos-5yrs w/ average FU of 30 mos (radiographic criteria: fusion on lat flex/ext radiographs) retrospective review of 23 pts over a $10-\mathrm{yr}$ period: 1 Type I, 16 Type II, 6 Type III, (radiographic criteria for fusion: no movement on lat flex/ext radiographs)

54 pts: 0 Type I, 38 Type II, 16 Type III (radiographic criteria for fusion: evidence of trabeculation across fx site $\&$ absence of movement on lat flex/ext radiograph)

retrospective review of 41 pts: 26 treated conservatively w/ tongs, four-poster brace, collars $\&$ halo vests for an average of 12 wks: 0 Type I, 13 Type II, 13 Type III (radiographic criteria for fusion: union on plain radiograph \& tomogram as well as lat flex/ext views; nonunion defined as movement of the dens fragment on lat flex/ext radiographs)

80 pts treated w/ either fixation for $2-4$ mos $\&$ then collar immobilization for $4-6 \mathrm{wks}$, or immobilization w/ traction for 2-6 wks $\&$ then rigid bracing [SOMI brace] for 3-6 mos followed by additional collar support for $6 \mathrm{wks}$; minimum 6 mos, w/ 80\% having FU $>8$ mos (radiographic criteria: fusion on lat flex/ext radiographs at 3-4 mos)

retrospective review of 52 pts: 24 treated conservatively: 1 Type I, 9 Type II, 14 Type III. (radiographic criteria: fusion demonstrated on AP \& lat CT scans)

14 pts: 0 Type I, 9 Type II, 5 Type III w/ a 2 -yr FU period, placed in halo \& evaluated at $12 \mathrm{wks}$ w/ flex/ext radiography; if no movement of the OP in relation to body of the axis, the $\mathrm{fx}$ was deemed stable; otherwise treatment continued for another mo (radiographic criteria: fusion on lateral flex/ext radiographs)

41 pts: 0 Type I, 26 Type II, 15 Type III (treated for $1 \mathrm{mo}$ in traction $[2-4 \mathrm{Kg}]$, then w/ rigid collar for 6-8 wks, \& then assessed at 3 mos; radiographic criteria for fusion: bone continuity across fx site and no movement on flex/ext)

26 pts: 0 Type I, 17 Type II, 9 Type III (immobilized in halo for a minimum of 3 mos \& if no movement on flex/ext radiographs, pts were placed in a Philadelphia collor for an additional 4 wks; radiographic criteria for fusion: no movement or subluxation at fx site on flex/ext)

104 pts: 2 Type I, 62 Type II, 32 Type III ( 2 groups: 72 pts w/ fx identified w/in 3 wks of trauma; 32 pts w/ an extended period before treatment: 1 Type I, 21 Type II, \& 8 Type III)
III Type I: 2 fusions (100\%); Type II: 14 fusions (64\%), 8 nonunions (36\%); Type III: 12 fusions $(92 \%)$; 1 nonunion $(8 \%)$

III Type II: 9 fusions (37.5\%), 15 nonunions $(62.5 \%)$; Type III: 2 fusions (100\%)

III Type II: 6 fusions (50\%), 6 nonunions (50\%); Type III: 4 fusions $(80 \%), 1$ nonunions $(20 \% ; 1$ pt lost to FU): 4 deaths (3 Type II, 1 Type III)

III Type I: 1 fusion (100\%, 6 wk average); Type II: 9 fusions (60\%), 6 nonunions $(40 \%)$ (1 pt lost to FU; average FU 8 wks); Type III: 6 fusions $(100 \%$, average FU 7 wks)

III Type II: 25 fusions (66\%), Type III: 16 fusions (100\%)

III Type II: 6 fusions (46\%), 7 nonunions (54\%); Type III: 11 fusions (85\%), 2 nonunions $(15 \%)$

III

Type II: 40 fusions (68\%), 19 nonunions (32\%), (4 lost to FU); Type III: 15 fusions (100\%) (2 lost to $\mathrm{FU})$

III Type I: 1 fusion (100\%); Type II: 3 fusions (43\%), 4 nonunions (57\%) (2 pts lost to FU); Type III: 10 fusions (71\%), 3 malunions $(21 \%), 1$ nonunion $(7 \%)$

III 10 fusions (91\%) combined Type II \& Type III fx, 1 nonunion $(9 \% ; 3$ deaths)

III Type II: 19 fusions (73\%), 2 fibrous unions (8\%), 5 nonunions (19\%); Type III: 15 fusions $(100 \%)$ (no deaths, 7 halo pin-site infections, 3 skin excoriation over chin secondary to halter traction)

III Type II: 15 fusions (88\%), 2 nonunions (12\%); Type III: 9 fusions $(100 \%)$

III Type I: $100 \%$ fusion; Type II: 1 fusion (10\%), 2 malunions (20\%), 6 nonunions $(60 \%)$; Type III: 1 nonunion $(5.9 \%), 5$ malunions $(29.4 \%), 11$ unions $(64.7 \%)$ (of patients reported)

* AP = anteroposterior; $\mathrm{CT}=$ computerized tomography; flex/ext = flexion/extension; FU = follow up; fx = fracture(s); OP = odontoid process; $\mathrm{SOMI}=$ suboccipital mandibular immobilizer. 
TABLE 2

Treatment and outcome of odontoid by nonoperative or traction therapy in cases reported in the literature*

\begin{tabular}{|c|c|c|c|c|}
\hline Authors \& Year & Therapy & Description of Study & $\begin{array}{l}\text { Class of } \\
\text { Data }\end{array}$ & Outcome \\
\hline $\begin{array}{l}\text { Anderson \& } \\
\text { D'Alzono, } 1974\end{array}$ & $\begin{array}{l}\text { traction/ } \\
\text { collar }\end{array}$ & see Table 1 & III & see Table 1 \\
\hline Marar \& Tay, 1973 & traction & see Table 1 & III & see Table 1 \\
\hline $\begin{array}{l}\text { Clark \& White, } \\
1985\end{array}$ & traction & $\begin{array}{l}11 \text { pts: } 0 \text { Type I, } 3 \text { Type II, } 8 \text { Type III; } \\
\text { see Table I }\end{array}$ & III & $\begin{array}{l}\text { Type II: } 2 \text { fusions }(66 \%), 1 \text { nonunion } \\
\text { (33\%); Type III: } 7 \text { fusions }(88 \%) \text {, } \\
1 \text { malunion }(13 \%)\end{array}$ \\
\hline Pepin, et al., 1985 & $\begin{array}{l}\text { halo/ } \\
\text { traction }\end{array}$ & see Table 1 & III & see Table 1 \\
\hline Fuji, et al., 1987 & $\begin{array}{l}\text { halo/ } \\
\text { traction }\end{array}$ & $\begin{array}{l}\text { acute } \mathrm{fx} \text { w/ displacement were treated } \\
\text { w/ skull traction to obtain reduction, } \\
\text { then immobilized by means of halo } \\
\text { vest or plaster cast \& finally neck brace; } \\
\text { see Table } 1\end{array}$ & III & see Table 1 \\
\hline $\begin{array}{l}\text { Govender \& } \\
\text { Grootboom, } 1988\end{array}$ & $\begin{array}{l}\text { traction/ } \\
\text { collar }\end{array}$ & see Table 1 & III & See Table 1 \\
\hline Chiba, et al., 1996 & $\begin{array}{l}\text { traction/ } \\
\text { collar }\end{array}$ & 2 Type II; See Table 1 & III & $\begin{array}{l}\text { Type II: } 0 \text { fusions }(0 \%), 2 \text { nonunions } \\
(100 \%)\end{array}$ \\
\hline
\end{tabular}

* See Table 1 for description of additional study data.

associated with this procedure include loss of reduction of the fracture and development of new neurological deficits.

In four articles, anterior fixation was performed to treat cases of odontoid fractures (Table 4). ${ }^{6,9,13,17}$ No case of Type I odontoid fractures was reported in these four articles. In patients with Type II odontoid fractures who un- derwent anterior fixation, fusion was achieved in 66 (90\%) of 73 patients. Of 20 patients with Type III odontoid fractures, radiographic fusion was demonstrated in all. Thus, anterior cervical fixation can be considered a treatment option for cases of both Type II and Type III odontoid fractures. Currently anterior odontoid fixation in which lag screws are placed is the preferred approach. ${ }^{6,13,17}$

TABLE 3

Treatment and outcome of odontoid fractures treated by posterior cervical fixation

\begin{tabular}{|c|c|c|c|}
\hline Author \& Year & Description & $\begin{array}{l}\text { Class of } \\
\text { Data }\end{array}$ & Outcome \\
\hline Maiman \& Larson, 1982 & $\begin{array}{l}34 \text { of } 49 \text { Type II pts were treated w/ early posterior } \\
\text { wire/graft stabilization \& postop immobilization } \\
\text { w/ Minerva for an average of } 5 \text { wks; } 2 \text { Type III } \\
\text { pts \& } 0 \text { Type I (radiographic criteria for nonunion: } \\
\text { CT evidence of avascular necrosis, gross instability } \\
\text { w/ a demonstrable gap at the fx line, \& no evidence } \\
\text { of healing, results evaluated } 6 \text { mos postop }\end{array}$ & III & 17 fusions $(35 \%)$; mortality rate $4 \%$ \\
\hline $\begin{array}{l}\text { Waddell \& Reardon, } \\
\quad 1983\end{array}$ & $\begin{array}{l}24 \text { pts: } 20 \text { Type II, } 4 \text { Type III fx: } 16 \text { of the } 20 \text { Type II } \\
\text { fx were treated w/ C1- } 2 \text { arthrodesis (Gallie pro- } \\
\text { cedure); all Type III fx treated nonoperatively }\end{array}$ & III & $\begin{array}{l}\text { Type II: } 15 \text { fusions (94\%), } 1 \text { pt lost to FU; Type } \\
\text { III: } 3 \text { fusions ( } 75 \%), 1 \text { nonunion }\end{array}$ \\
\hline Clark \& White, 1985 & $\begin{array}{l}32 \text { pts treated w/ posterior fusion: } 26 \text { Type II, } \\
4 \text { Type III }\end{array}$ & III & $\begin{array}{l}\text { Type II: } 24 \text { fusions ( } 92 \% \text { ) ( } 2 \text { complications: } 1 \mathrm{fx} \\
\text { displacement } \& 1 \text { worsening myelopathy } \\
\text { thought to be secondary to wire placement); } \\
\text { Type III: } 4 \text { fusions }(100 \%)\end{array}$ \\
\hline Pepin, et al., 1985 & $\begin{array}{l}12 \text { of } 41 \text { pts treated surgically: } 1 \text { Type I, } 4 \text { Type II, } \\
7 \text { Type III; see Table } 1\end{array}$ & III & $\begin{array}{l}\text { Type I: } 1 \text { fusion (100\%); Type II: } 4 \text { fusions } \\
\text { (100\%); Type III: } 7 \text { fusions (100\%) }\end{array}$ \\
\hline Dunn \& Seljeskog, 1986 & $\begin{array}{l}42 \text { pts treated w/ posterior cervical fusion: } 37 \text { Type } \\
\text { II \& } 5 \text { Type III w/ chronic injuries, nonunion after } \\
\text { skeletal fixation \& acute injuries }\end{array}$ & III & $\begin{array}{l}40 \text { of } 41 \text { fusions ( } 98 \% \text { ) of combined Type II \& } \\
\text { Type II fx, } 1 \text { nonunion ( } 2 \% \text { ) (1 death) }\end{array}$ \\
\hline Fuji, et al., 1987 & 7 of 52 pts treated w/ posterior fusion: 7 Type II & III & 7 fusions $(100 \%)$ \\
\hline Coyne, et al., 1995 & $\begin{array}{l}15 \text { pts treated w/ posterior wire fusion \& immobilized } \\
\text { postop in either Philadelphia collor or halo; minimun } \\
\text { FU } 2 \text { yrs, mean } 4.7 \text { yrs (radiographic criteria for } \\
\text { fusion: absence of C1-2 movement on lat flex/ext } \\
\text { radiographs \& evidence of continuity of trabecular } \\
\text { bone formation between C1 \& C2 across the graft }\end{array}$ & III & Type II: 13 fusions ( $87 \%), 2$ nonunions \\
\hline Chiba, et al., 1996 & $\begin{array}{l}10 \mathrm{pts} \text { treated w/ posterior cervical fusion: } 7 \text { Type II } \\
\text { nonunion fx, } 2 \text { Type II fx identified w/in } 3 \text { wks, \& } \\
1 \text { irreducible Type III fx identified w/in } 3 \text { wks }\end{array}$ & III & $\begin{array}{l}\text { Type II: } 9 \text { fusions (100\%); Type III: } 1 \\
\text { fusion }(100 \%)\end{array}$ \\
\hline
\end{tabular}


TABLE 4

Treatment and outcome of odontoid fractures treated by anterior cervical/transoral fixation

\begin{tabular}{|c|c|c|c|}
\hline Authors \& Year & Description of Study & $\begin{array}{l}\text { Class of } \\
\text { Data }\end{array}$ & Outcome \\
\hline Bohler, 1982 & $\begin{array}{l}15 \text { pts w/ acute and chronic OP fx treated w/ anterior } \\
\text { screw fixation followed by fixation in a plastic } \\
\text { collar for } 4-16 \text { wks: } 8 \text { Type II, } 7 \text { Type III (radio- } \\
\text { graphic criteria for fusion not given) }\end{array}$ & III & Type II: 8 fusions (100\%); Type III 7 fusions \\
\hline Fuji, et al., 1987 & $\begin{array}{l}10 \text { pts treated w/ anterior screw fixation: } 0 \text { Type I, } \\
8 \text { Type II, } 2 \text { Type III }\end{array}$ & III & $\begin{array}{l}\text { Type II: } 6 \text { fusions (75\%), } 2 \text { nonunions }(25 \%) \text {; } \\
\text { Type III: } 2 \text { fusions }(100 \%)\end{array}$ \\
\hline Dickman, et al., 1995 & $\begin{array}{l}14 \text { pts w/ acute or subacute Type II fx (radiographic } \\
\text { criteria for fusion: postop radiographs and CT scans) }\end{array}$ & III & 14 fusions $(100 \%)$ \\
\hline Chiba, et al., 1996 & $\begin{array}{l}45 \text { pts underwent anterior screw fixation: } 35 \text { Type II, } \\
10 \text { Type III (transoral pts: } 8 \text { Type II \& } 1 \text { Type III; } \\
\text { radiographic criteria for fusion not given) }\end{array}$ & III & Type II: 8 fusions (100\%); Type III 7 fusions (100\%) \\
\hline
\end{tabular}

Complications include retropharyngeal wall injury, misplaced screw, screw fracture, infection, and injury to surrounding vascular and neural structures. ${ }^{6,13,17}$ Attempts at odontoid fixation by performing a transoral approach have been shown to yield significant complications. ${ }^{9}$

\section{DISCUSSION}

This review indicates that there are currently no treatment standards available to guide the care of all three types of odontoid fracture. Additionally, no treatment guidelines can be determined based on the review of the available literature. The four treatment options that do exist are halo or Minerva vest therapy, traction followed by immobilization in a cervical collar, posterior cervical fusion, and anterior fixation.

For Type I and Type III fractures, immobilization tends to yield satisfactory results in $100 \%$ and $84 \%$ of cases, respectively, although the number of cases is limited. Anterior fixation for treatment of Type III fractures appears to improve the fusion rate $(100 \%)$.

For Type II fractures, halo vest immobilization and posterior fixation were shown to yield relatively similar fusion rates $(65 \%$ and $74 \%$, respectively). Anterior fixation appears to increase the fusion rate $(90 \%)$, whereas traction alone is less successful (57\%).

These observations are based entirely on the review of Class III data that are inadequate to establish either a treatment standard or guideline. Therefore, all management modalities described remain treatment options.

\section{CONCLUSIONS}

More data are necessary to determine treatment standards and/or guidelines for the management of the three types of odontoid fracture. For Type I and Type III fractures the available Class III evidence suggests that a welldesigned case-controlled study could provide evidence to establish a practice guideline for cervical immobilization for 6 to 8 weeks as appropriate management in the initial treatment. This is based on the fact that in the reported cases, immobilization appeared to be an adequate treatment. Unfortunately, there were limited numbers of reported cases, and all the data that we obtained were classifed as Class III. A well-designed, prospective study or a case-controlled retrospective study would potentially allow the creation of a clinical guideline. For Type II fractures, analysis of results reported in the literature suggests that both operative and nonoperative management remain treatment options. In this case, there is no clear trend found even in the available Class III data. Although larger numbers of cases are reported and are available for analysis, there is no clear consensus among the investigators, leaving only treatment options. Because this remains a more controversial issue, a randomized or series of well-designed prospective studies will be required to establish a practice guideline or treatment standard for this fracture type.

\section{References}

1. Alker GJ, Oh YS, Leslie EV: Postmortem radiology of head and neck injuries in fatal traffic accidents. Radiology 114:611-617, 1975

2. American Medical Assocation: Attributes to Guide the Development and Evaluation of Practice Parameters/Guidelines. Chicago: American Medical Association, 1996

3. Anderson LD, D'Alonzo RT: Fractures of the odontoid process of the axis. J Bone Joint Surg 56 (Am):1663-1674, 1974

4. Apfelbaum RI, Papadopoulos, SM, Polinsky M, et al: Treatment of Type II odontoid fractures, in Al-Mefty O, Origitano TC, Harkey HL (eds): Controversies in Neurosurgery. New York: Thieme, 1996, pp 286-293

5. Benzel EC, Hart BL, Ball PA, et al: Fractures of the C-2 vertebral body. J Neurosurg 81:206-212, 1994

6. Bohler J: Anterior stabilization for acute fractures and nonunions of the dens. J Bone Joint Surg 64 (Am):18-27, 1982

7. Bracken MB, Freeman DH Jr, Hellenbrand K: Incidence of acute traumatic hospitalized spinal cord injury in the United States, 1970-1977. Am J Epidemiol 113:615-622, 1981

8. Bucholz RD, Cheung KC: Halo vest versus spinal fusion for cervical injury: evidence from an outcome study. J Neurosurg 70:884-892, 1989

9. Chiba K, Fujimura Y, Toyama Y, et al: Treatment protocol for fractures of the odontoid process. J Spinal Disord 9:267-276, 1996

10. Clark CR, White AA III: Fractures of the dens. A multicenter study. J Bone Joint Surg 67 (Am):1340-1348, 1985

11. Coyne TJ, Fehlings MG, Wallace MC, et al: $\mathrm{C} 1-\mathrm{C} 2$ posterior cervical fusion: long-term evaluation of results and efficacy. Neurosurgery 37:688-693, 1995

12. Davis D, Bohlman H, Walker AE: The pathological findings in fatal craniospinal injuries. J Neurosurg 34:603-613, 1971 
13. Dickman CA, Foley KT, Sonntag VKH, et al: Cannulated screws for odontoid screw fixation and atlantoaxial transarticular screw fixation. Technical note. J Neurosurg 83:1095-1100, 1995

14. Dunn ME, Seljeskog EL: Experience in the mangement of odontoid process injuries: an analysis of 128 cases. Neurosurgery 18:306-310, 1986

15. Ekong CE, Schwartz ML, Tator $\mathrm{CH}$, et al: Odontoid fracture: management with early mobilization using the halo device. Neurosurgery 9:631-637, 1981

16. Ersmark H, Lowenhielm P: Factors influencing the outcome of cervical spine injuries. J Trauma 28:407-410, 1988

17. Fuji E, Kobayashi K, Hirabayashi K: Treatment in fractures of the odontoid process. Spine 13:604-609, 1988

18. Govender S, Grootboom M: Fractures of the dens-the results of non-rigid immobilization. Injury 19:165-167, 1988

19. Hadley MN, Dickman CA, Browner CM, et al: Acute axis fractures: a review of 229 cases. J Neurosurg 71:642-647, 1989

20. Huelke DF, O'Day J, Mendelsohn RA: Cervical injuries suffered in automobile crashes. J Neurosurg 54:316-322, 1981

21. Kraus JF, Franti CE, Riggins RS, et al: Incidence of traumatic spinal cord lesions. J Chronic Dis 128:471-492, 1975

22. Lind B, Nordwall A, Sihlbom H: Odontoid fractures treated with halo-vest. Spine 12:173-177, 1987

23. Maiman DJ, Larson SJ: Management of odontoid fractures. Neurosurgery 11:471-476, 1982
24. Marar BC, Tay CK: Fracture of the odontoid process. Aust NZ J Surg 46:231-236, 1976

25. Pepin JW, Bourne RB, Hawkins RJ: Odontoid fractures, with special reference to the elderly patient. Clin Orthop (193): $178-183,1985$

26. Rosenberg J, Greenberg MK: Practice parameters: strategies for survival into the nineties. Neurology 42:1110-1115, 1992

27. Ryan MD, Taylor TKF: Odontoid fractures. J Bone Joint Surg 64 (Br):416-421, 1982

28. Waddell JP, Reardon GP: Atlantoaxial arthrodesis to treat odontoid fractures. Can J Surg 26:255-258, 1983

29. White AA III, Panjabi MM: Clinical Biomechanics of the Spine, ed 2. Philadelphia: JB Lippincott, 1990, pp 92-97

30. Woolf SH: Practice guidelines: a new reality in medicine. III. Impact on patient care. Arch Intern Med 153:2646-2655, 1993

Manuscript received April 18, 2000.

Accepted in final form May 10, 2000.

Address reprint requests to: Timothy C. Ryken, M.D., Division of Neurosurgery, University of Iowa Hospitals and Clinics, 200 Hawkins Drive, Iowa City, Iowa 52242-1061. email: timothy-ryken @uiowa.edu. 